\title{
A Virtue Ethical Approach to Interpretation of the Suffering Other
}

\author{
Anne Eggert Stevns ${ }^{1}$ \\ ${ }^{1}$ Aarhus University, Department of Philosophy and History of Ideas, Jens Chr. Skous Vej 7 , \\ 1465/523, 8000 Aarhus C, Danmark
}

\begin{abstract}
In this article my aim is to take up a thread from an article by Svend Brinkmann, wherein he is anxious to show that mental suffering cannot exclusively be explained within the narrow vocabulary of medical diagnosis systems, but can, an should be, be articulated through a large range of 'interpretive vocabularies' (Brinkmann 2014). In line with Brinkmann's emphasis on the large range of possible interpretive vocabularies, I will engage the moral philosopher Iris Murdoch to show how the exploration of different possible interpretations of a particular client's situation is in fact an ethical task, which requires the practitioner's personal development of virtue in terms of selfless, loving attention as the precondition for a realistic interpretation of the client's situation.
\end{abstract}

Keywords: mental suffering, interpretation, ethics, selfless love, Iris Murdoch

\section{Introduction}

Mental suffering occurs in a vast variety of forms, and there is an equally vast variety of articulations of the experience of it. A prolonged sense of sadness could be understood in many different ways, and perhaps more at the same time. It could for instance be understood as a clinical depression, a result of political suppression, a moral mistake of infidelity, or be given a religious explanation in terms of sin, etc. If we relate this to the professional area that has specialised in dealing with mental distress, how should mental health professional then ideally try to understand the suffering patient or client in order to help him or her in the best possible way? Should they only turn to scientifically tested diagnostic explanations, or should they allow for other kinds of articulations of suffering, as for instance religious, moral or political ones?

In this article my aim is to take up a thread from an article by Svend Brinkmann, wherein he is anxious to show that mental distress cannot exclusively be explained within the 
narrow vocabulary of medical diagnosis systems, but can, and should be, be articulated through a large range of 'interpretive vocabularies' (Brinkmann 2014). In line with Brinkmann's emphasis on the large range of possible interpretive vocabularies, I will engage the moral philosopher Iris Murdoch to show how the exploration of different possible interpretations of a particular client's situation is in fact an ethical task, which requires the practitioner's personal development of virtue in terms of selfless, loving attention as the precondition for a realistic and helpful interpretation of the client's situation.

\section{Interpretive Agents}

Before turning to Murdoch's attempt to connect the process of interpretation with the ethical task of selfless love, I begin by looking at Brinkmann's suggestion that human beings are primordially meaning-creating (interpretive), which means that the practitioner needs to focus on and develop a broader awareness of different kinds of vocabularies than the narrow biomedical diagnostic one, when trying to make sense of the situation of a suffering client. However, his aim is not to reject the legitimacy of - and need for - highly specialised medical explanations of mental distress or suffering. Rather his aim is to point to the limits of reductive bio-medical explanations, which indicate the need for other types of interpretations. Very briefly put, the limit consists in the fact that a diagnostic explanation, when taken as a strict reductive bio-medical explanation, can only articulate causal relations in physical objects, in this case the brain and perhaps other parts of the body (Brinkmann 2014, p. 644). But this kind of explanation excludes a very important part of human reality, namely the fact that that the body is the body of a human person, who is not merely an object of physical causes, but a subjective agent, who is able to articulate experience through language and to actively position herself and give reasons for her actions in light of these articulations (Brinkmann 2014, p. 640). Brinkmann is of course aware that the current diagnostic manuals within psychiatry (DSM 5) do not merely approach patients as a bunch of physio-biological mechanisms, but in fact often help patients to externalise their symptoms in order for them to be able to cope with their problems. Thus, psychiatrists do in fact respond to patients as self-positioning agents that can learn to actively cope with their problems through for instance psychoeducation, patient communities, development of personal responsibility for daily exercises etc. (Brinkmann 2014, p. 644). However, Brinkmann's point is that the vocabularies that are used in relation to such externalisations are exactly those kinds of vocabularies that "specialise" in agential language, such as for instance a political, religious or moral one. His suggestion is thus not to reject the 
usefulness of reductive bio-medical explanations, but to emphasise that in relation to mental health issues, we should always see languages that position patients as agential persons as primary and of main importance (Brinkmann 2014, p. 644).

Brinkman finds his main inspiration in the pragmatism of Richard Rorty and the hermeneutics of Charles Taylor. From Rorty he takes the idea that the vocabularies through which we try to understand reality should not aim at 'objective truth' in terms of traditional correspondence-truth, but should rather aim for providing fruitful options for agency and enhance the client's ability for autonomous self-positioning (Brinkmann 2014, p. 644). However, the limitation of the pragmatist approach is that its strong emphasis on the enhancement of human autonomy and agency runs the risk of unrealistic subject-positioning. Brinkmann thus argues that the pragmatist appeal to vocabularies as 'tools' for agency must be supplemented by a 'hermeneutic interest' in describing (interpreting) the particular context of the client, so that an overly optimistic agent-positioning can be avoided, for instance by positioning clients as agents in relation to matters where there is no realistic possibility for actions that can relieve suffering (e.g. kinds of incurable or chronical disease, psychosis, severe depression etc.) (Brinkmann 2014, p. 645). It is this last appeal to careful attention to the particular situation of the client that is of main importance for my argument here.

In relation to the task of creating a realistic interpretation of the client, it is important that Brinkmann emphasises the inherently normative task for the practitioner to decide through what kind(s) of vocabulary(ies) she can possibly make sense of a client's experience of suffering, and that very often it is possible to make sense of the same experience of suffering through several vocabularies at the same time. For instance, it is possible to make sense of the experience of a prolonged sense of sadness in several ways: it can be described as clinical depression, as the result of an unhappy marriage, a troubled childhood, a stressful working environment, worries about economics or the climate crisis and so on. Each of these interpretations open up for different possibilities for subject-positioning (self-interpretation) and action, and it might be that more of these descriptions would be fitting at the same time in different degrees.

However, what Brinkmann does not develop is an account of what the normative task of creating a realistic interpretation of the client exactly amounts to. How does one know, when one has gained a realistic picture of the client? What does 'realistic' even mean in this context? And how does one do it? These questions do of course lie beyond the aim of Brinkmann's article, which is rather an attempt to map and appeal to the importance of different interpretive vocabularies that accommodate individuals as agents responsive to norms rather than merely 
physio-biological causal chains as it is found in most medical diagnostic systems (Brinkmann 2014, p. 644).

My aim is to look at how Iris Murdoch could provide a possible answer to the questions that arise from Brinkmann's suggestion. With Murdoch, I will argue that by looking at the phenomenology of interpretation, which in this context amounts to looking at the process of interpretation from a first-person perspective of experience, ${ }^{1}$ we can become aware of how realistic (truthful) ${ }^{2}$ interpretation is, not 'merely' a task of finding fitting normative spaces for the client to move within (in the sense that various vocabularies set up different 'dos and don'ts' for agency, i.e. different 'spaces of reasons'). It is also an explicitly personal ethical (or moral) ${ }^{3}$ task inevitably connected with the practitioner's development of the virtue of loving, selfless attention as the precondition for realistic interpretation and positioning of the client. This means that, to exemplify, we could say that a 'space of reasons/norms' would be opened up if a client's suffering was, for instance, interpreted as a result of an unhappy marriage. This reading would be a reason for the client to consider a divorce, which would again position her as someone (at least partly) responsible for taking action and finding a solution. On Murdoch's view, a part of the task for the practitioner would be to attend carefully to the client's account of the marriage, which inevitably involves that the practitioner tries to describe (to picture) the relation for herself in order to be able to orient herself in the complex situation of the client as realistically as possible, and to search for new possible vocabularies for her to move within.

The ability to evaluate, compare and finally decide the most proper and helpful and hence good course of action is what Murdoch takes to be the core of Plato's idea of virtue as the 'striving for the Good'. An illuminating example of virtue as the ability to make a right decision based on a careful and proper view of the situation can be found in her Platonic essay The Sovereignty of Good. Here Murdoch at one point compares virtue to what the Greeks called techne, which refers to crafts, sciences, and various intellectual disciplines (Murdoch 1997, p. 373). In our context, this could mean that for a mental health professional to be virtuous, she

\footnotetext{
${ }^{1}$ Murdoch's view of the phenomenological tradition as a 'philosophical school' is in some regards critical and she does not identify herself as a phenomenologist in the way for instance Husserl, Heidegger and Sartre do. However, her aim of exploring human morality is very much in line with traditional phenomenological approaches to questions of value and morality that begin from a first-person perspective of experience with the aim of understanding how ethical questions become meaningful to subjective experience in the first place, and commits itself to work within the limits of experience (Loidolt 2018, p. 699; Browning 2018, p. 52; Murdoch 1989; Murdoch 1992, p. 241).

${ }^{2}$ It is very important that the terms 'realistic' and 'truthful' do not refer to the classical epistemological realismidealism debate, but are being used as moral virtue-terms referring to every day experiences of being 'honest' and 'faithful' to a situation.

${ }^{3}$ Murdoch uses the terms ethical and moral interchangeably without differentiating between the two.
} 
ought at least to be skilled and is for instance required to have a lot of scientific and theoretical background knowledge. The important thing is, however, that virtue (knowing what is good to do in a particular situation) can never be reduced to knowledge of various kinds of techne. Rather, knowing the good is knowing, for instance, when a certain skill should be used or held back, what facts one should take to be decisive in a contradictory and pressing situation, etc. To exemplify that understanding, what is good is ultimately superior to possessing certain teachable skills. Murdoch for instance says: "A serious scholar has great merits. But a serious scholar who is also a good man knows not only his subject but the proper place of his subject in the whole of his life" (Murdoch 1997, p. 378). As is already implicit here, this means that 'learning' to discern what is good is not something one can 'be taught' in the same way that one can be taught a craft, but an inner, personal development of careful, just, and loving ways of looking at (and hence also describing) particular situations (a certain 'way of being'), through which one becomes able to do what one is able to see as good. ${ }^{4}$

To return to the practitioner's inevitably descriptive evaluation of her client, Murdoch would argue that these descriptions and re-descriptions almost inevitably contain (sometimes very subtle) uses of metaphors and adjectives that inform us of the outlook of the practitioner and her implicit or explicit morally sensitive evaluations of better or worse, true and false (Murdoch 1992, p. 243). This could for instance appear in uses of colour (a sense of a greying relation, a faded glow) or space (a claustrophobic relation) or mood (a roaring lion, a state of war), or in the preference of one vocabulary over another (e.g. a view of the 'darkness' of a religious response to suffering in terms of sin as compared to a less 'heavy' and more 'gentle' secular interpretation in terms of a moral error). What I will demonstrate in the following is thus Murdoch's claim that the use of various vocabularies or 'spaces of reasons' for action are always already morally 'coloured' by the user (here the practitioner) because they inevitably already contain (at least to some degree) her own continuous discriminations of true and false, better and worse. I will show how Murdoch is anxious to emphasise that the task of describing another person's situation is morally significant in the sense that it moves within a continuum from 'selfish distortion' to 'selfless vision', which amounts to the ability to see from the perspective of the client's situation and not automatically impose one's own preferred perspective on the situation. Murdoch's claim is that 'quality of consciousness' is morally significant, because it forms the entire evaluative imaginative background against which we

\footnotetext{
${ }^{4}$ For a detailed discussion of the Platonic notion of 'knowing the Good' see also Gadamer's illuminating text on the matter (Gadamer 1986, pp. 33-63).
} 
discern good from bad, right from wrong, and that it is morally important that this evaluative background is as true to reality outside the egoistic mind as possible (Murdoch 1997, p. 369). To be rather crude, one could say that Murdoch introduces the problem of evil (in terms of a human egoistic refusal to attend properly to others) into Brinkmann's picture as an obstacle to realistic interpretations that cannot easily be 'switched off' and 'bracketed out', but is present as a continuous threat that must be kept on a tight leash: "The egoistic (personal) formulation and distortion of reality reaches right down to the base of unenlightened cognition, and one cannot by a [single] reflective move cancel it" (Murdoch 1992, p. 241). We shall return to this issue shortly.

However, the challenge of egoism means that acquiring a realistic vision of the other (a realistic description of her situation) is inevitably connected to the development of a 'good quality of vision', which involves the subtle business of description and redescription, undistorted by egoistic desires that tend to 'colour' our world, often below the levels of immediate awareness. This exercise requires the virtue of selfless, loving attention:

\footnotetext{
"Should a retarded child be kept at home or sent to an institution? Should an elderly relation who is a trouble-maker be cared for or asked to go away? [...] The love which brings the right answer is an exercise of justice and realism and really looking. The difficulty is to keep the attention fixed upon the real situation and to prevent it from returning surreptitiously to the self with consolations of self-pity, resentment, fantasy and despair. The refusal to attend may even induce a fictitious sense of freedom: I may as well toss a coin. [...] It is a task to come to see the world as it is" (Murdoch 1997, p. 375).
}

Of course, there is also a task for the client to develop a truthful vision of her own situation, but due to the limited scope of this article, I shall only relate Murdoch's position as to the interpretive task of the practitioner faced with a suffering other (the client) and not go into the (of course not entirely unrelated) task of the client to create a realistic picture of her own situation. This is also related to the nature of Murdoch's philosophical project, in which she conceives of the ethical task of human beings as the continuous movement away from the ego and towards reality beyond it. Thus, her strength lies in describing this movement of individual consciousness (here the practitioner) trying to imagine the reality of the world and others (here the client) as they exist outside her, often limited, vision of reality. This is of course not an attempt to say that practitioners faced with clients are generally egoistic and narrow-minded and that Murdoch's suggestions are necessarily the only tools for improvement. Rather, it is an attempt to yield an honest picture of how all human beings are (to some degree) limited and 
self-protective creatures, raised within different contexts with a limited amount of psychological resources for careful attention to others, and to argue that the process of realistic interpretation is inevitably a personal moral task of transcending selfishness through loving attention. $^{5}$

Thus, the main thesis of the article is that if Murdoch's picture of the human experience of the world and others is accepted, this means that a realistic interpretation of others is necessarily connected to the virtue of loving attention, which would require the personal development of this attitude of 'selfless attention' in practitioners trying to understand and help suffering clients as autonomous and independent individuals. However, before moving on it should be noted that Murdoch's moral philosophy has not before been discussed in relation to the practical field of mental health care, or indeed any 'applied' field. In this context it is not my intention to develop any sort of Murdochian 'code of conduct' for mental health practitioners, and I believe it was never Murdoch's intention to do any such thing either. Rather, I suggest, her thought can provide fields engaged in understanding and/or helping other people with a critical awareness of, and a vocabulary for articulating, the moral challenges inherent in the concrete and context-bound task of understanding others.

In spite of their different approaches to the question of love and care for others, I suggest that Murdoch could be placed within a similar category of proximity-ethics as philosopher K. E. Løgstrup, who is already a well-known figure within the Scandinavian healthcare system. ${ }^{6}$ For both, the primary ethical phenomena are the concrete needs that occur in particular individual contexts, as opposed to for instance universally valid principles for duty (deontology) or maximation of utility (consequentialism). However, for Murdoch the primary focus on the personal development of loving attention, of 'unselfing', does not exclude other kinds of moral reasoning (e.g. utilitarian or deontological), but these should be "seen in [the] wider landscape" of the continuous imaginative and evaluative activity of the human mind (Murdoch 1992, p. 302). Thus, Murdoch's 'ethics of love' would not be directly applicable as for instance a political tool for setting rules and standards regarding recruitment of health-care professionals, patient rights, prioritization of economic resources etc. In these matters she refers us to political morality, which is not entirely unrelated to personal moral orientations,

\footnotetext{
${ }^{5}$ To avoid misunderstandings regarding the ontological status of intersubjectivity, it should be noted that Murdoch is sympathetic to Heidegger's phenomenological rejection of the old Cartesian problem about how the subject reaches the world and others, which means that, at an ontological level, we are always already affectively involved with our surroundings and others humans (Murdoch 1993, p. 25). The barrier of selfishness that she refers to is thus, as far as I can see, a psychological one (Murdoch 1997, p. 377).

${ }^{6}$ See for instance Kari Martinsen's Care and Vulnerability (2006).
} 
but nevertheless works at a different level mainly governed by general principles and rights claims (Murdoch 1992, p. 348).

\section{Egoism and Distorted Interpretation}

In the following, I will take a closer look at Murdoch's claim about the moral orientation of the self and relate it to the question about the practitioner's moral task of relating to a suffering client. As it is perhaps already partly clear from the above, the main source of our inability to 'see' others clearly cannot be reduced to a lack of 'factual objective information' in a morally neutral sense, but is, on Murdoch's view, directly connected to the "more or less fantastic reverie" of selfish desire that distorts our inevitably evaluative descriptions and imaginations of others (Murdoch 1997, p. 364).

As Maria Antonaccio has already thoroughly developed, a distinct feature of Murdoch's moral philosophy is her suggestion that moral philosophy should not find its main inspiration from attempted value-neutrality of the domain of the natural sciences, but rather find its main inspiration in the field of aesthetics (Antonaccio 2012). An important aspect of this suggestion can, I suggest, be described as a naturalist critique not far from the one Brinkmann directs at reductive and value-neutral natural science. As Murdoch and Brinkmann would agree, the important critique is that we do not primordially relate to the world as a neutral world of (scientific) objects and then subsequently prescribe value to them, but instead we primordially come to construct interpretively 'fabricate' the world in light of our aims and desires before we come to look at it through the detached lens of the natural sciences (Murdoch 1997, pp. 199201; Bagnoli 2011, p. 209).

The distinct feature of Murdoch's position regarding our 'aims and desires' is that, in contrast to for instance a pragmatic (Rorty, Brinkmann) or Heideggerian explanation of the fundamental 'guiding principle' of our intentions, she sees love, in terms of a Platonic notion of desire-love (Eros), as the moving principle and 'spiritual-sexual energy' of all human

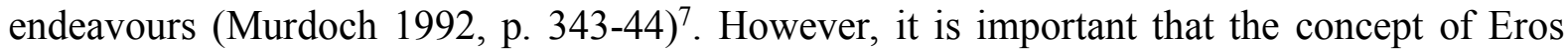
(love) signifies human desire-love as a continuous tension, mythically depicted in the Symposium as an "ambiguous spirit, the child of Poverty and Ingenuity [...] poor and homeless and without shoes like his mother, but brave and ingenious like his father" (Murdoch 1992, p. 343). Thus, human desire-love works at different levels and can, on the one hand, signify the most degraded being of humans, for instance when love works as an imprisoning vehicle for

\footnotetext{
${ }^{7}$ See for instance Gary Browning's short analysis of Murdoch's reading of Heidegger (Browning 2018, 44-54).
} 
the satisfaction of the ego. However, Eros is at the same time also the 'cure' to the problem of selfishness and the distorted vision of egoistic desire, because when properly cultivated, it can express the highest form of satisfaction available to humans (Murdoch 1992, p. 346). This kind of purified satisfaction comes about when love (Eros) is actively turned away from the "easy rat-runs' of the ego and directed selflessly towards the world and others outside of the self, simply for the sake of the goodness we experience as inherent in such kind of love that joins us to the world and others instead of isolating us in anxious self-protection (Murdoch 1997, p. 384). Murdoch borrows the guiding idea of this re-orientation from Plato's idea of perfect virtue in terms of 'the Good' as the ideal moral standard for all human desire, depicted in Plato's Republic in the analogy of the Sun.

I will return to Murdoch's defence of the Good as the sovereign moral ideal for human desire-love below, but first we shall look at what Murdoch's idea of human selfishness (low Eros) amounts to, in order to make sense of how this can be related to our case about a practitioner trying to understand her client. In The Sovereignty of Good, Murdoch draws both on Plato's vision of the self in terms of Eros-love as a continuous movement between illusion and truthful vision of reality (the parable of the Cave in the Republic), but she also adds modern psychological findings in order to, I suggest, substantiate her use of Platonic imagery and deploy it in a modern context. In this regard, she implicitly refers to Freud's major influence on her time when she states that in relation to human selfishness, "modern psychology has had something to tell us" (Murdoch 1997, p. 364). Thus, she defines human selfishness as the 'lower', 'base' and almost 'mechanical' part of the self that fundamentally functions as a selfprotective 'machine' moving along in continuous striving for self-preservation and satisfaction:

"The psyche is a historically determined individual relentlessly looking after itself. In some ways it resembles a machine; in order to operate it needs sources of energy, and it is predisposed to certain patterns of activity. [...] It is reluctant to face unpleasant realities. Its consciousness is not normally a transparent glass through which it views the world, but a cloud of more or less fantastic reverie designed to protect the psyche from pain. It constantly seeks consolation, either through imagined inflation of self or through fictions of a theological nature. Even its loving is more often than not an assertion of self. I think we can probably recognise ourselves in rather depressing picture" (Murdoch 1997, p. 364). 
Murdoch's main claim is thus that egoism reveals itself not merely as outward 'bad behaviour', but already at the level of our 'inner' conversation with ourselves and the often slightly dishonest or simplified pictures and fantasies we create of ourselves and others. On Murdoch's view, this activity should thus be conceived of as a continuous threat to our interpretive orientation that potentially influences the whole of our outlook, and not something that merely happens occasionally as for instance minor 'slips' or outrages of fear and anger.

Rather, Murdoch argues, our "minds are continuously active, fabricating an anxious, usually self-preoccupied, often falsifying veil which partially conceals the world", and because of this our 'states of consciousness' are morally important because they are "profoundly connected with our ability to choose and act" (Murdoch 1997, p. 369, original emphasis). To relate this to our case about the practitioner trying to make sense of her client, this means that the practitioner would be, like everyone else, perhaps without even noticing it, continuously more or less drawn towards the easy satisfaction of the ego, which inevitably influences her ability to 'see' from the perspective of the client and make the best choices of what to do. As it was already hinted at above, Murdoch sees this self-protective aspect of our attachment to the world and others as potentially dangerous when we (here the practitioner) try to understand the reality of other people, because we might turn to easy, pleasing, but false interpretations and thus fail to see the particular and complex situation that confronts us.

The main drive of selfishness is, on Murdoch's view, strongly connected to our inescapable need to protect our frail and incomplete being; we want to avoid painful realities that disturb our psychological need for a sense of harmony and being in control, and we surreptitiously work on reality to make it more harmless and manageable than it often is. We are full of more or less fantastic illusions about our own capacities, and we very often turn the reality that confronts us into something familiar and pleasing in order to conceal possible disturbances of our stable self-being. Reflecting upon our common use of simplified aesthetic forms to make sense of others, Murdoch thus suggests: "The true story may not even look like a story because it will inhibit the automatic movement of egoism, with its imposition of pleasing and innocuous form. We want to control the tale ourselves and give it our ending [...]. We want to make a move to a conclusion, our conclusion" (Murdoch 1992, p. 105). As already exemplified above, this can also be observed in more subtle forms that immediately does not seem to have anything to do with egoism, for instance the setting of a professional practitioner trying to understand a client. This could, for instance, show itself as a practitioner's personal preference of some kinds of interpretive vocabularies as opposed to others, which could 
perhaps be a result of a too dogmatic endorsement of one particular methodology, personal indolence, unrecognised trauma, personal career plan, fear of the sometimes insurmountable complexity of particular others that surpass theoretical categorisations etc. As exemplified above, Murdoch's point is that all such biases reveal themselves in the very 'fabric' of the progressive picturesque evaluations of true and false, better and worse that makes up the life of the individual consciousness and gives it its particular 'colour', and this already establishes a very complex and often opaque background for any deliberations on what we can (and should) realistically do to help the other. I thus agree with Carla Bagnoli when she, in her recent comparison of Murdoch and Kant, argues that what matters most to Murdoch is "how the fabric is woven, and the irreducible particularity of the weft", whereas for a Kantian "what matters is the warp, that is, the structure that sustains particular fabrics" (Bagnoli 2018, p. 83). A result of this, the solution to the threat of egoism is not primarily the control of contingent 'fabric' of desires through moral principles, but rather the development and transformation of the quality of the individual weft.

\section{Love and Truthful Interpretation}

What Murdoch suggests is that if the continuous presence of the 'fat relentless ego' is a truthful picture of (at least a part of) the human mind, "then everything which alters consciousness in the direction of unselfishness, objectivity and realism is to be connected with virtue" (Murdoch 1997, p. 369).

We have now looked at Murdoch's claim about the inevitable aspect of egoism in our attachment to the world and others, which strongly influences our ability to interpret their situation without the distortion of ego. But how does she reach the conclusion that realistic and hence good interpretations require the virtue of selfless, loving attention? She does so by investigating the connection between the experience of selflessness, goodness, and truthfulness from within experience itself (from a first-person perspective), which is the only place where it can be seen how "the concept of virtue is tied on to the human condition" (Murdoch 1997, p. 371). As Fiona Tomkinson has drawn attention to, Murdoch's conception of virtue as the transcendence of the self, marks her departure from a Freudian model that would suggest an 'integration' of the divided self as the best to be hoped for, i.e. the balancing of the ego between the id and the super ego (Tomkinson 2019, p. 59). In Murdoch's comparison of Freud and Plato in the essay The Fire and The Sun she expresses her disagreement with Freud's exclusively sexual reading of the concept of the libido that he found in Plato, whereby Freud reduced the 
general moving principle of human motivation to the attainment of sexual satisfaction (Murdoch 1997, pp. 418-19; Murdoch 1992, p. 23). Instead, Murdoch turns to Plato's more 'ambitious' vision of the fundamental source and locus of human motivation in the myth of Eros-love as necessarily related to the idea of goodness as the perfection of this love (the idea of the Good), which comes about as active transcendence of the self that happens through a self-forgetful integration with the world and others.

In Sovereignty Murdoch finds the cue to the connection between a loving selfless vision/interpretation and virtue in certain kinds of experiences that occasion 'unselfing' - a term Murdoch translates from Simone Weil's decreation ${ }^{8}$ - through which initial narrowminded preoccupation is thwarted, followed by the joyful and liberated experience of joining a more truthful picture of the world beyond initial prejudice, fear, indolence etc. (Murdoch 1997, p. 369). Initially, Murdoch turns to a very simple and common-sense example of how the experience of beauty in nature can occasion moments of selfless attention. She explains how one's anxious and resentful state of mind due to a trivial preoccupation with a possible damage done to one's prestige can suddenly be interrupted by the appearance of hovering kestrel outside the window. Suddenly attention is entirely fixated on the beauty of the kestrel and the vain self-preoccupation disappears for a moment (Murdoch 1997, p. 369). In turning to nature, "we take a self-forgetful pleasure in the sheer alien pointless independent existence of animals, birds, stones and trees" (Murdoch 1997, p. 370). Here we see the first attempt to exemplify how goodness is connected with the immediate self-forgetful integration with external reality. But a single example with the perception of a bird outside a window will not do the trick to convince us that selfless vision (love) of the other is required to interpret her situation adequately.

For our purposes, it is important that if a good interpretation is connected with good quality of attention, this makes the (virtue of) purification of (Eros-love) a necessary personal practice for the practitioner. Murdoch uses the example with attention to nature to link our immediate selfless love of natural beauty to the much more complex region of our love of beauty in human made works of art and relates these to the development of virtuous attention. Initially, she admits, love of beauty in nature or art does not seem to have much to do with the moral task of loving attention to others, but, she suggests, if we take Plato's point seriously that "beauty is the only spiritual thing we love by instinct", we shall soon be able to see how love of beauty in works of art is, if not completely identical to (love of) goodness, at least very close

\footnotetext{
${ }^{8}$ See Simone Weil's Gravity and Grace (2002).
} 
to it (Murdoch 1997, p. 370). In contrast to most other - typically neo-Aristotelian - virtue ethical positions, Murdoch insists that "art is the great clue to morals", because it is in great works of art, particularly the novel, full of truthful portrayals of the detailed and complex reality of the human scene, that a truthful and loving vision of human individuals can be seen and experienced as genuinely good (Murdoch 1997, p. 372). Murdoch's emphasis on beauty as a primary source of inspiration of Eros is remarkably underexposed in much recent literature on Murdoch's philosophy, where it is often framed as one possible experience among a range of others that occasion the aspiration for a truthful vision of the world and others. ${ }^{9}$ Much attention is generally given to the role of creative imagination as a way to practice unselfing, but very little attention is given to beauty as that which sets the whole process in motion.

In contrast, I would argue that Murdoch places the experience of beauty as the key source of moral inspiration. This means that, on Murdoch's view, the beauty we enjoy in art should be understood as the enjoyment of a truthful vision of reality, which amounts to the beauty of human virtue, the purified love through which the artist portrays (that is interprets) reality as good as she can. This is, I contend, what Murdoch means when she argues that "[Great art] invigorates our best faculties and, to use Platonic language, inspires love in the highest part of the soul. It is able to do this partly by virtue of something which is shares with nature: a perfection of form which invites unpossessive contemplation and resists absorption into the selfish dream life of the consciousness" (Murdoch 1997, p. 370).

As was already hinted at above, a truthful (realistic) interpretation of others cannot be reduced to the collection of 'factual information', but is the result of a sustained attempt to try to imagine reality from the point of view of the other. Murdoch gives an illuminating example from Henry James' novel The Golden Bowl, where we follow the inner experience of the main character Maggie, who has slowly realised that her husband has an affair with her best friend. James' achievement is that he succeeds in picturing the whole atmosphere of this emerging awareness in a way not entirely unlike (although much more loaded with symbols) the way we continuously picture and evaluate ourselves and our surroundings

"This situation has been occupying, for months and months, the very centre of the garden of her life, but it had reared itself there like some strange tall tower of ivory, or perhaps rather some wonderful, beautiful, but outlandish pagoda, a structure plated with hard bright porcelain, coloured and figured

\footnotetext{
${ }^{9}$ See for instance (Antonaccio 2012, p. 114) or (Broackes 2011).
} 
and adorned, at the overhanging eaves, with silver bells that tinkled, ever so charmingly, when stirred by chance airs" (Murdoch 1992, p. 170).

Thus, the achievement of great artists is obviously not an ability to strip their depictions of characters and their surroundings from evaluative words. The point is rather that language is inevitably evaluative, deeply influenced by the direction of our desires. The task of the artist, in relation to his work, is thus to purify his desire in the sustained struggle for a truthful understanding of the matter at hand: "The realism of a great artist is not a photographic realism, it is essentially both pity and justice" (Murdoch 1997, p. 371). This is the sense in which "the perfection of form' in art resembles the perfection of form in morals, because both are 'unified' by the same aspiration towards the perfection of love: "Art and morals are, with certain provisions, one. [...] The essence of both of them is love. Love is the perception of individuals. Love is the extremely difficult realisation that something other than oneself is real. Love, and so art and morals, is the discovery of reality" (Murdoch 1997, p. 215). This idea of the perfection of love directed at particular others, never entirely psychologically reachable for limited, mortal human beings, is what Murdoch articulates through Plato's idea of the Good, pictured in the analogy of the Sun in the Republic - it is both the light through which we come to see reality, since we cannot escape continuously discriminating between true and false in our depiction of reality, but it is at the same time the unreachable (and as such transcendent) magnet that draws us towards its centre as the ideal moral standard for the truth-seeking mind.

Finally, we should ask how this relates to the everyday setting of a practitioner trying to understand a client? Obviously, we are not all great artists, and if truthful understanding only occurs in the greatest of art, the hopes are not high for the lot of us. However, Murdoch's reference to the work of great artists is not to be read as elitist as one might immediately do in the sense that only artists have the capability of moral development. On the contrary, Murdoch insists that the beauty of great art can, and often does, work as an inspiration for the 'artists' that we all are, in so far as we are imaginative creative users of language, through which we continuously describe and redescribe ourselves and others (Murdoch 1992, p. 322). Murdoch thus insists that "[t]he work of imagination in art may be seen as a symbol of its operation elsewhere", and defines it, in opposition to egoistic 'fantasy' as the "ability to picture what is quite other [than oneself]" (Murdoch 1992, p. 322). We are now able to see how the requirement of loving attention to the client is not a question of 'falling in love' in a romantic sense of the term, but refers to virtue as the need for the practitioner to perform a kind of continuous 'double movement' when attending to a client; on the one hand she must actively 
'unself' in order to make sure that she is not distorted by personal preference, fear, envy, etc., and one the other, she must aim for empathetic imagination of the situation of the client, in order to be able to make the best suggestions of what to do in relation to the clients experience of suffering. This is the way in which I suggest that Murdoch's picture could very well be seen as an extension of Brinkmann's view by adding a moral-psychological perspective on what is required to interpret the concrete situation of a particular client.

\section{References:}

Antonaccio, Maria (2012): A Philosophy to Live By - Engaging Iris Murdoch, Oxford University Press.

Bagnoli, Carla (2011): 'The Exploration of Moral Life' in Iris Murdoch - Philosopher, J. Broackes (ed.), Oxford University Press.

(2018): 'Constrained by Reason, Transformed by Love: Murdoch on the Standard of Proof' in Murdoch on Truth and Love, Palgrave Macmillan.

Brinkmann, Svend (2014): 'Languages of Suffering' in Theory \& Psychology 2014, Vol. 24(5) 630-648.

Broackes, Justin (ed.)(2011): Iris Murdoch - Philosopher, Oxford University Press.

Browning, Gary (2018): Why Iris Murdoch Matters, Bloomsbury.

Gadamer, Hans-Georg (1986): The Idea of the Good in Platonic-Aristotelian Philosophy, Yale University Press.

Martinesen, Kari (2006): Care and Vulnerability, Akribe.

Loidolt, Sophie (2018): 'Value, Freedom, Responsibility: Central Themes in Phenomenological Ethics' in The Oxford Handbook of the History of Phenomenology, Dan Zahavi (ed.), Oxford University Press.

Murdoch, Iris (1992): Metaphysics as a Guide to Morals, Penguin Vintage. (1997): Existentialists and Mystics - Writings on Philosophy and Literature, Penguin Books.

(1993): Heidegger (Unpublished book manuscript), Iris Murdoch Archive, University of Kingston KUAS6/5/1/4.

(1989): Sartre - Romantic Rationalist, London: Penguin Books.

Tomkinson, Fiona (2019): 'Murdoch's Question of the Work of Art: The Dialogue Between Western and Japanese Conceptions of Unity' in Reading Iris Murdoch's 'Metaphysics as a Guide to Morals', N. Hämäläinen and G. Dooley (eds.), Palgrave Macmillan. 
Weil, Simone (2002): Gravity and Grace, Routledge.

\begin{abstract}
About the Author:
Anne Eggert Stevns is a PhD-student in Philosophy, Aarhus University. She is currently working on Iris Murdoch's reception of the existential-phenomenological tradition via a study of her book manuscripts on J.-P. Sartre and Martin Heidegger. Her main academic interests are existential and moral philosophy.
\end{abstract}

